\title{
Promotion of self-management in vulnerable older people: a narrative literature review of outcomes of the Chronic Disease Self-Management Program (CDSMP)
}

\author{
Angèle A. G. C. Jonker • Hannie C. Comijs • \\ Kees C. P. M. Knipscheer • Dorly J. H. Deeg
}

Published online: 7 November 2009

(c) The Author(s) 2009. This article is published with open access at Springerlink.com

\begin{abstract}
With ageing, older people can become frail, and this has been shown to be associated with a decrease in well-being. Observational studies provide evidence of a positive effect of coping resources on well-being. The question is: can coping resources be improved in vulnerable older people? The Chronic Disease Self-Management Program (CDSMP) is a target group-specific intervention which aims to promote the self-management of older people who are confronted with deteriorating health. The aim of this study was to review intervention studies focusing on the CDSMP and to draw conclusions on the benefits of the program. A systematic search was conducted in PubMed and PsychINFO to identify randomized controlled trials (RCTs) focusing on the CDSMP. Nine RCTs focusing on relatively young older adults, $75 \%$ of whom with an average age between 49 and 65 years, were included. We found that the CDSMP was consistently beneficial for Health behaviour, especially with regard to the variables of exercise and self-care. For Health status, the majority of studies only showed improvement in the domain of health distress. Most of the studies that
\end{abstract}

A. A. G. C. Jonker - H. C. Comijs - K. C. P. M. Knipscheer ·

D. J. H. Deeg

Department of Psychiatry, EMGO Institute for Health and Care Research, VU University Medical Centre,

Amsterdam, The Netherlands

A. A. G. C. Jonker - H. C. Comijs - K. C. P. M. Knipscheer -

D. J. H. Deeg

Faculty of Social Sciences, VU University, Amsterdam,

The Netherlands

A. A. G. C. Jonker ( $\square)$

LASA/EMGO, VU University Medical Centre, Van der

Boechorststraat 7, 1081 BT Amsterdam, The Netherlands

e-mail: ag.jonker@vumc.nl investigated Self-efficacy showed convincing improvement in self-efficacy, cognitive symptom management and mental stress management. In Health care utilization, there was no significant decrease. On the whole, the studies showed that CDSMP led to an increase in physical exercise, a decrease in health distress, an improvement in selfcare, and it had a beneficial effect on self-efficacy.

Keywords Review - Chronic disease management program $\cdot$ Health $\cdot$ Coping $\cdot$ Intervention

\section{Introduction}

The majority of older people especially those with nursing needs have a compromised health status, accompanied by functional and cognitive decline (Crimmins et al. 1996; Crimmins 2004, Robine and Mitchel 2004 and Schram et al. 2008a, b), because they have more than one, often interacting, diseases (i.e. multimorbidity). Approximately $60 \%$ of the general older population (55 years and above) are confronted with multimorbidity. The prevalence increases to $95 \%$ of older persons from 85 years and above. For older persons with high nursing needs, such as those in care facilities, the prevalence of multimorbidity is $80 \%$ and does not differ by age and sex (Schram et al. 2008a, b).

Because of the worldwide increase in life-expectancy, an increase in the number of older people with health decline can be expected. Older people who are confronted with deteriorating health often experience lower levels of well-being (Kunzmann et al. 2000; Landau and Litwin 2001; Jonker et al. 2008), and as a consequence, many older people find it difficult to maintain control over their lives and to retain a certain feeling of self-worth. In order to retain a good feeling of self-worth, coping resources 
appear to play an important role. The availability of coping resources may influence patients' self-appraisal of their situation and enable them to deal adequately with the demands of their disease(s) (Folkman et al. 1986). In addition, the availability of coping resources such as mastery, self-esteem and self-efficacy may buffer the negative influence of deteriorating health on well-being, as has been demonstrated in several studies (Bandura 1977; Folkman et al. 1988; Jang et al. 2002; Bisschop et al. 2004a and Jonker et al. in press). However, these coping resources are under pressure, due to deteriorating health (Larson et al. 1984 and Bisschop et al. 2004b). One could speak of a downward spiral of deteriorating health and a decrease in coping resources and well-being (Artistico et al. 2000) which constantly have a negative influence on each other.

In order to optimize the well-being of the growing population of vulnerable older people, one approach to break through the vicious circle may be to enhance their coping resources to empower those people. Self-management is proposed as one of the ways in which older people can more actively manage their own ageing process by increasing the availability of coping resources, and as a consequence, their well-being is increased and maintained as long as possible (Steverink et al. 2005).

The Chronic Disease Self-Management Program (CDSMP) is a structured intervention developed by Kate Lorig, which emphasizes the strengthening of self-management in older people with multiple chronic conditions to empower them to stay in control of their own body and life (Lorig 1996; Lorig et al. 1999, 2001a, b). The National Health Service in the United Kingdom has adopted an amended version of the American CDSMP as its main selfmanagement educational program and is licensed to implement the CDSMP (Lorig 1996). The CDSMP is the only intervention that focuses on older people with one or more chronic diseases, regardless of the specific disease and that aims to stimulate them to become more actively involved in the management of their own health and to enable them to take care of themselves (Elzen et al. 2006). The advantage of this general management program is that it focuses not so much on the problems related to one specific disease, but on the problems encountered during the course of the disease, such as fatigue, pain and anxiety, which are the same for patients with different chronic diseases.

Many studies have published reports on this intervention, but the sample characteristics, study design, measurements and outcome variables vary widely between these studies. Because of the disparate presentation of various results and the small amount of available high quality studies, we chose to perform a narrative review of randomized controlled trials (RCTs) instead of a metaanalysis of the many of uncontrolled studies with incomparably presented results.
The aim of our narrative review was to examine the effectiveness of the CDSMP and to investigate whether this intervention does indeed, deserve to be further implemented in populations of vulnerable older people.

\section{The Chronic Disease Self-Management Program (CDSMP)}

The main aim of the CDSMP is to assist people to cope with multiple chronic diseases. It is based on prior experience with an arthritis self-management program, a literature review, various needs assessments and the theoretical framework of self-efficacy (Bandura 1977 and 1997; Lorig et al. 1999). Three principal assumptions that underlie the CDSMP are:

1. People with different chronic diseases have similar self-management problems and disease-related tasks.

2. People can learn to take responsibility for the day-today management of their diseases.

3. Confident, knowledgeable patients practicing selfmanagement will experience improved health status and will utilize fewer health care resources.

Two additional requirements are:

1. Self-management education should be inexpensive and widely available.

2. Trained laypersons with chronic conditions can effectively deliver a structured patient education program.

The CDSMP focuses on several topics, including physical exercise, nutrition, breathing, emotions, communication and medication, which are discussed during 6-weekly sessions of $2^{1 / 2} \mathrm{~h}$ each in groups of $10-15$ participants. The groups are supervised by two trained leaders.

The underlying mechanism that explains the positive effects on health behaviour, health status, self-management behaviour and health care utilization, is assumed to be selfefficacy. This is defined as 'believing in one's own capability to organize and execute the courses of action required to produce given attainments' (Bandura 1997). The concept of self-efficacy refers to personal judgements of how well one's own behaviour can be implemented in situations that contain novel, unpredictable, or stressful elements as well as ordinary situations. If people think that a certain behaviour will lead to a certain outcome, they will adopt that behaviour, but only if they consider themselves able to do so (Bandura 1977). The CDSMP incorporates strategies to enhance self-efficacy, and thereby to enhance selfmanagement behaviour and health-related outcomes: weekly action planning and feedback, participants modeling behaviour and problem-solving for each other, re-interpretation of symptoms, group problem-solving and individual decision-making (Lorig et al. 2000). 


\section{Materials and methods}

\section{Search strategy}

In order to identify CDSMP intervention studies, a systematic search was conducted through the published article resources of PubMed (end date April 18, 2008) and PsychINFO (end date April 18, 2008). When applicable, thesaurus and MESH terms were used. The search terms: coping resources, well-being, intervention, health/aged/ frailty, lead to the keywords: CDSMP, self-efficacy, selfesteem, mastery, adaptation psychological, coping, internal-external control, decision-making, problem-solving, quality of life, well-being, life satisfaction, valuation of life, positive affect, patient education, self-help groups, intervention, aged, health status indicators, geriatric assessment and Kate Lorig (who developed the CDSMP). The literature search identified a total of 700 possibly relevant articles: PubMed 603 and PsychINFO 97. ${ }^{1}$

\section{Inclusion procedure}

All the articles matching one or combinations of the search terms were evaluated on the basis of title, key words, abstract and also full text. The inclusion criteria were: (1) CDSMP or EPP (English Patient Program which is an adaptation of the CDSMP), (2) physical group sessions, (3) RCTs and (4) having been published in peer-reviewed journals. As it was our aim to review the effectiveness of the program, we included only RCTs with a waiting list and/or care as usual control group. The exclusion criteria were: (1) Assessment/process evaluations, (2) internet or bibliographic appliance, (3) qualitative studies and (4) cost as the sole outcome.

\section{Results}

From a total of 700 potentially relevant articles, a total of 66 appeared to be relevant for analyses. Based on the title and keywords, 634 articles were found to be irrelevant, mainly due to other (younger) age-groups or specific disease categories. Pre/post-test designs were also already mentioned in the title, as well as specific control groups. After reading the abstracts, another 32 articles were excluded. The full text of the remaining 34 articles was then read in extensor, after which an additional 25 were excluded on the basis of the criteria for inclusion and exclusion. Eight of these articles did not concern an RCT. The other most frequent reasons for exclusion were either

\footnotetext{
$\overline{1}$ The search strategy is available on request from the corresponding author.
}

the fact that the study focused on other educational programs were used, or on CDSMP, process evaluations, internet participation and cost outcomes only. Three studies were excluded because the control group attended an alternative course, such as Tai-Chi, instead of receiving care as usual while on a waiting list. A total of nine studies, which fulfilled all the inclusion criteria, were included in the review. In one of these studies, two separate research questions were addressed in the same sample (Richardson et al. 2008; Kennedy et al. 2007) resulting in separate publications about the same intervention. Table 1 presents the sample characteristics, study design and results of the nine studies.

The designs of the studies varied widely. For instance, the follow-up ranged from 6 weeks (one study), to 4-6 months (nine studies), whereas one study included a 1-year follow-up. Some studies had both short- and also on longer-term follow-ups. The respondents had a variety of cultural and ethnic backgrounds: African American, Asian, Latino and White ethnicity. Five studies focused on majority ethnic groups (Elzen et al. 2006; Lorig et al. 1999; Kennedy et al. 2007; Richardson et al. 2008; Haas et al. 2005), and four studies focused on minority ethnic groups (Griffiths et al. 2005; Fu Dongbo et al. 2003; Lorig et al. 2003 and Swerissen et al. 2006). A total of $90 \%$ of the studies included groups of patients with heterogeneous chronic diseases, including those with comorbid conditions. Only Haas et al. (2005) included a homogeneous group of respondents with low back pain. The vast majority of the participants were female $(>75 \%)$. Among the nine studies the youngest sample had a mean age of 49 years (Griffiths et al. 2005), whereas the oldest sample had a mean age of 77 years (Haas et al. 2005). In many of the studies, the participants were relatively young older adults with average ages between 49 and 65 years (75\%).The sample sizes varied from 109 (Haas et al. 2005) to 954 (Fu Dongbo et al. 2003). With regard to other characteristics, such as types of teachers, lessons and group sizes (Table 1, other characteristics), there were very few differences between the studies. However, the number of sessions attended did differ between the studies and varied from zero to seven sessions. Some studies reported a high mean attendance of 5.6 (Elzen et al. 2006) and 5.3 (Swerissen et al. 2006) from six sessions. In the study of Kennedy et al. (2007), participants who attended at least four sessions were included. Some studies included all the patients of the intervention group, irrespective of the number of sessions that was attended (Griffiths et al. 2005). The diseases that the patients suffered from were (combinations of) diabetes, asthma, arthritis, cardiovascular diseases, lung diseases and cancer. Only one study included participants specifically suffering from low back pain (Haas et al. 2005). 


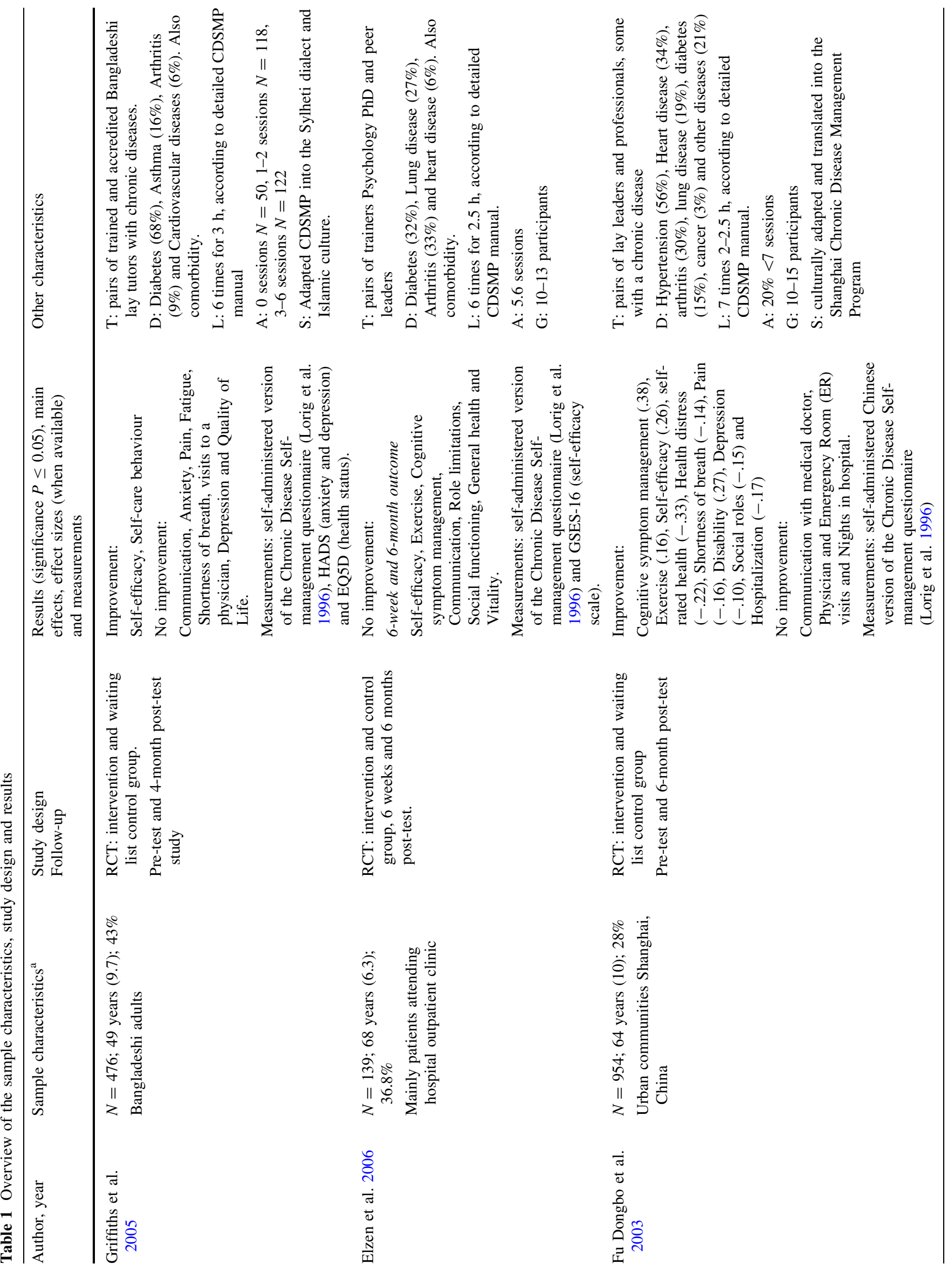




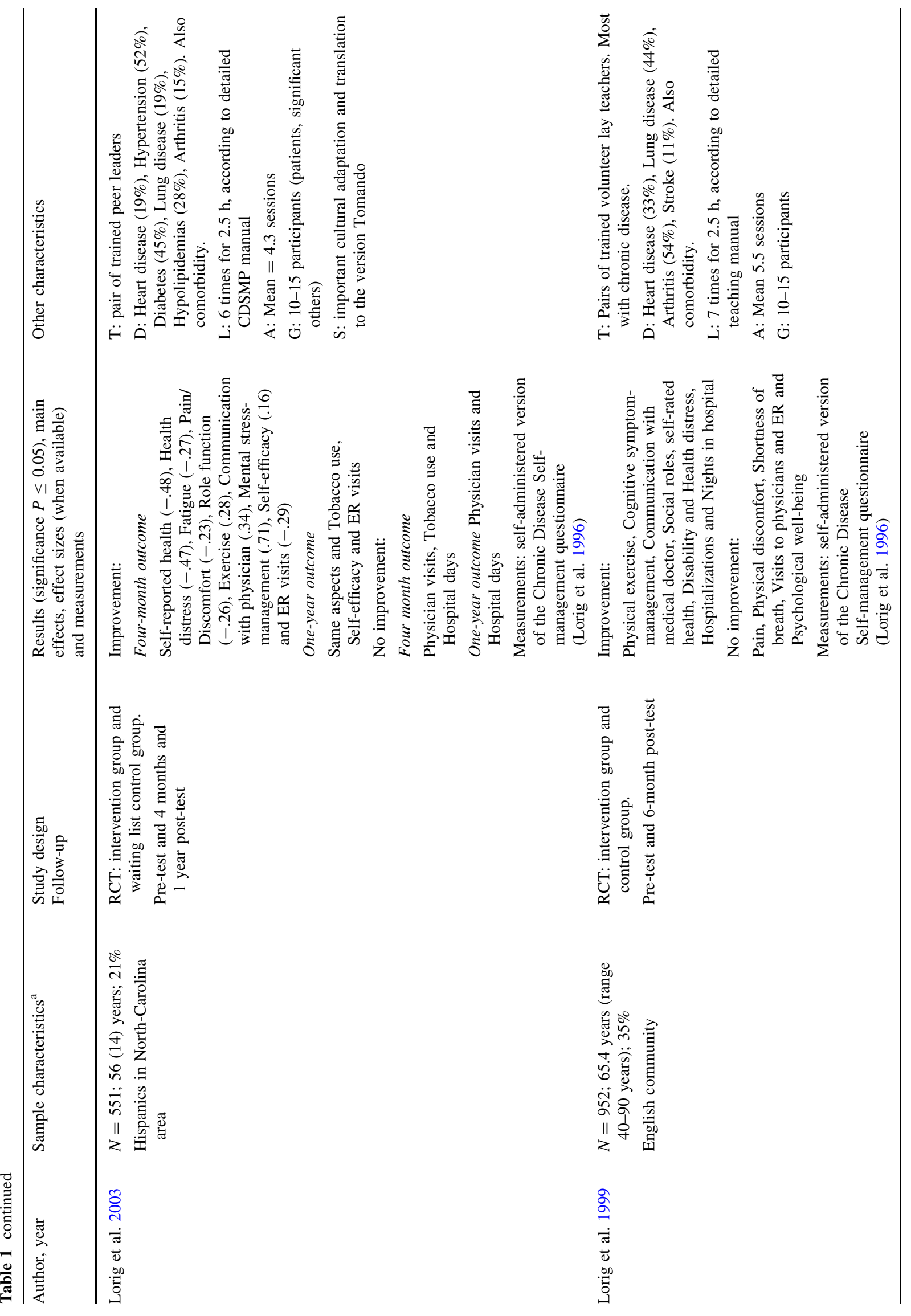




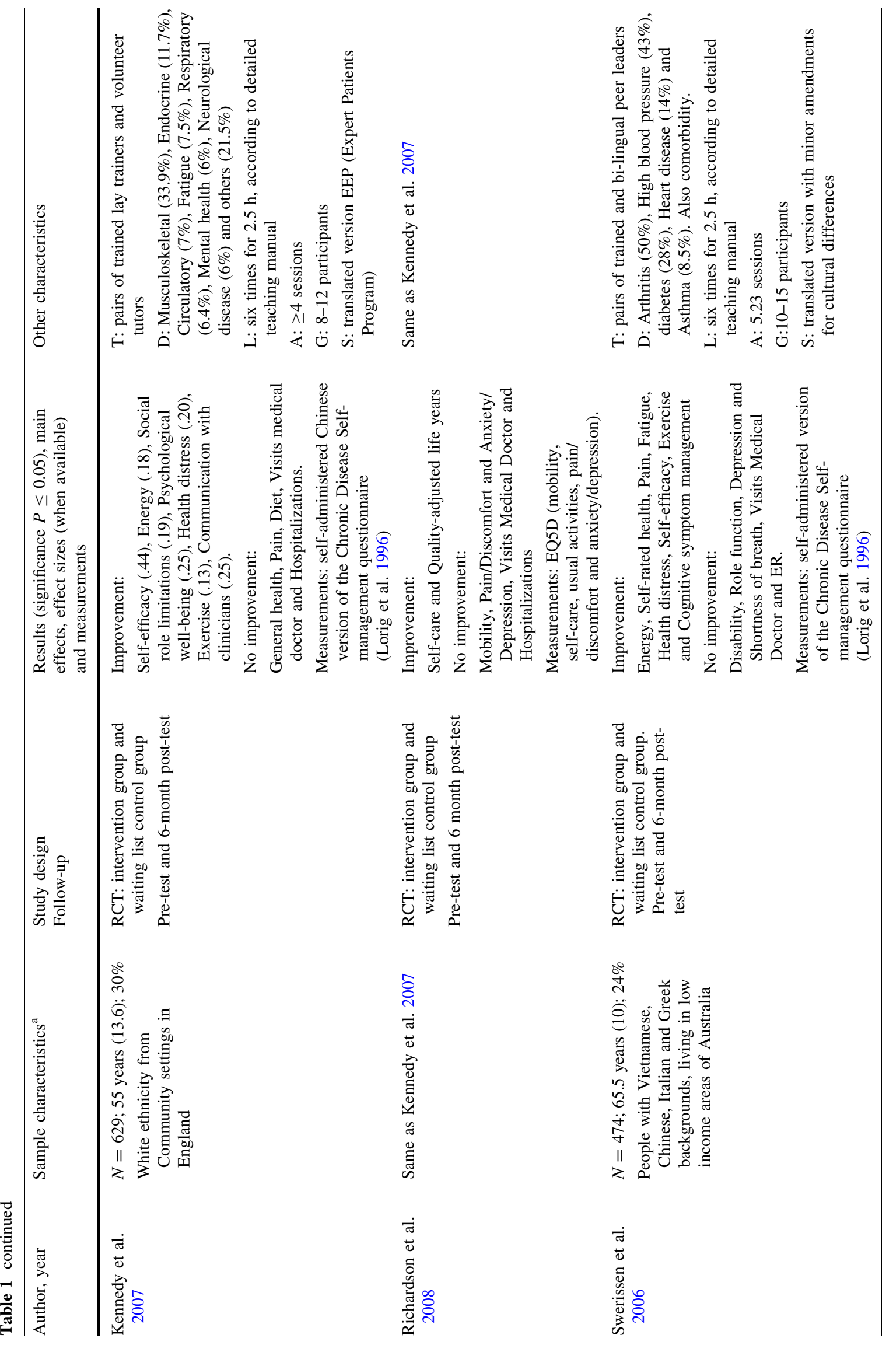


All of the studies adhered to the written CDSMP manual that details both the content of the course and the process (Lorig et al. 2000). In some studies, the original program was adapted to the culture and translated: Shanghai CDSMP (Fu Dongbo et al. 2003), Tomando (Lorig et al. 2003) and Expert Patients Program (Kennedy et al. 2007; Richardson et al. 2008). Swerissen et al. (2006) also translated the CDSMP and made minor amendments. Almost all of the studies made use of the Chronic Disease Self-management questionnaire (Lorig et al. 1996), but Richardson et al. (2008) and Haas et al. (2005) used other measurement instruments. Only three studies-Fu Dongbo et al. (2003) and Lorig et al. (1999 and 2003)—reported effect sizes varying between -0.10 and 0.38 , whereas 0.20 is assumed to be a small effect.

Classification of the results

In describing the results we followed the original CDSMP classification model of coping resources (Lorig 1996): Self-efficacy, Health behaviour, Health status and Health care utilization (see Fig. 1). The causal mechanisms of the current intervention are potentially multifaceted. Previous study suggests a theoretical model (Fig. 1) where the primary causal mechanism is change in self-efficacy, with changes in self-care behaviour secondary. Changes in selfefficacy are hypothesized to lead directly to changes in health status, which in turn influences healthcare utilization (Kennedy et al. 2007).

If an outcome measure deviated from the chosen classification, we categorized the outcome according to its specific characteristics, e.g. smoking was added to the category Health behaviour.

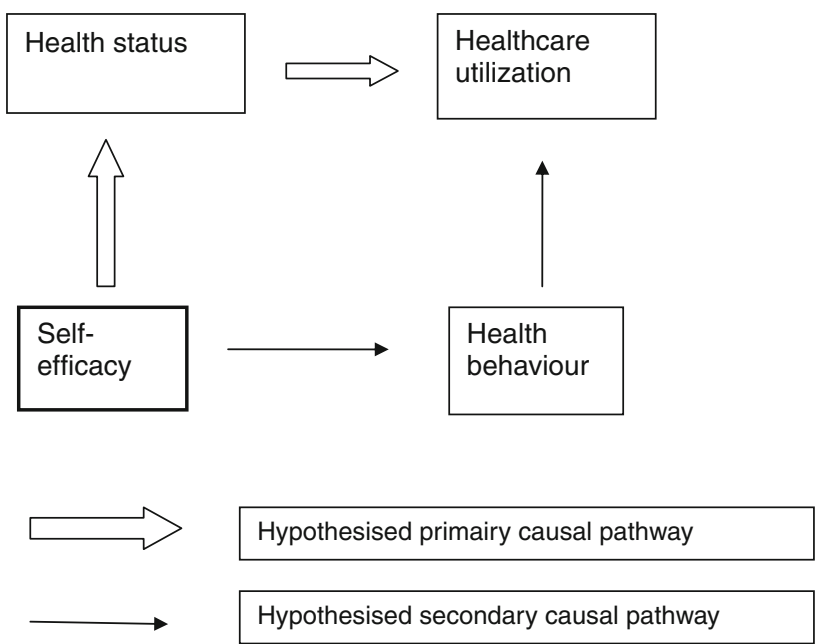

Fig. 1 Derived from the theoretical framework for outcome measurement CDSMP (Kennedy et al. 2007) 
Interpretation of the results was sometimes difficult because of the unequivocal presentation of the results in the various studies, i.e. the variation in outcome measures within the main categories that were presented.

\section{Health behaviour}

Health behaviour can largely be defined as behavioural aspects contributing to healthy living. All the studies appeared to focus on five components of Health behaviour: self-care, communication with physicians, healthy diet, smoking and exercise, the significance reported on which was very diverse. We, therefore, present the results for each of these components (see Table 2).

Self-care was studied in three RCTs, all of which had a 4-6 month follow-up. Two of these studies found an improvement in self-care in relatively large sample sizes of 476-629 persons. The participants had heterogeneous chronic diseases and were relatively young, with a mean age-range of 49-55 years. The study of 109 patients with low back pain and an average age of approximately 77 years did not show improvement in self-care.

Six studies reported on Exercise, including all types of physical exercises, such as strength training, stretching, walking and aerobics. Five of these studies, which reported an that showed improvement had large sample sizes (474952 respondents) with a mean age-range of 55-65.5 years. Improvement was also reported at the 1-year follow-up (Lorig et al. 1999). Only one study found improvement in Exercise: a Dutch RCT with 139 participants with a somewhat greater average age of 68 years.

The effect of the CDSMP on Communication with physicians was more diffuse.

The three studies that reported improvement had large sample sizes, varying from 551 to 952 participants, with a mean age-range of 55-65.4 years. The three studies that found no improvement varied in sample sizes from 139 to 954 participants who had mean ages ranging from 49 to
68 years, which did not differ from the studies in which no improvement was found. Follow-ups differed from 6 weeks to 6 months after the start of the CDSMP, but this did not lead to significant results.

The two studies that focused on a healthy diet (Kennedy et al. 2007) and to quit smoking (Lorig et al. 2003) found no improvement in either health behaviour at the 4-6 month follow-up. However, after 1 year, many participants in the CDSMP had stopped smoking.

Health status

Health status can be defined as mental and physical health conditions. The studies included in the review measured health distress, fatigue/energy, self-rated health, disability/ mobility, social roles, pain, discomfort, shortness of breath and anxiety (see Table 3). Well-being outcomes were measured as a part of Health status. The effects of CDSMP on the components of Health status appeared to be very diverse.

All of the studies $(N=5)$ that included Health distress as an outcome reported a significant improvement. Fatiguel Energy measured in six RCTs and reported an improvement in four studies. In the participants with a mean age of 58 years, fatigue/energy was found to be improved at 6-month follow-up. The studies with the youngest (49 years) and the oldest (77.2 years) participants reported no improvement. With respect to General (self-rated) health, four studies found an improvement, whereas three studies with smaller sample sizes did not.

The results vary considerably with regard to Disability/ mobility and Social roles. Two studies found a beneficial effect of CDSMP, whereas three other studies did not. There were no clear differences between the study samples. For Pain, Discomfort, Shortness of breath and Anxiety, studies reported hardly any improvement. Out of the eight studies that measured Pain, five found no significant effect of CDSMP, whereas three studies focusing on specific
Table 2 Summary of results with respect to Health behaviour

a $1=$ FU after 6 weeks;

$2=$ FU after $4-6$ months;

$3=\mathrm{FU}$ after 1 year; $4=\mathrm{FU}$

after 2 years

\begin{tabular}{llllll}
\hline Component & $\begin{array}{l}\text { Improvement }(+) \\
\text { No improvement }(-)\end{array}$ & $\begin{array}{l}\text { Number of } \\
\text { studies }\end{array}$ & $\begin{array}{l}\text { Range of } \\
\text { mean ages }\end{array}$ & $\begin{array}{l}\text { Sample } \\
\text { sizes }\end{array}$ & $\begin{array}{l}\text { Follow-up } \\
(\text { FU })^{\mathrm{a}}\end{array}$ \\
\hline Exercise & + & 5 & $55-65.5$ & $474-952$ & $2-3$ \\
& - & 1 & 68 & 139 & $1-2$ \\
Healthy diet & + & 0 & & & \\
& - & 1 & 55 & 629 & 2 \\
Tobacco & + & 1 & 57 & 551 & 3 \\
& - & 1 & 57 & 551 & 2 \\
Communication & + & 3 & $55-65.4$ & $551-952$ & $1-2$ \\
& - & 3 & $49-68$ & $139-954$ & $1-2$ \\
Self-care & + & 2 & $49-55$ & $476-629$ & 2 \\
& - & 1 & 77.2 & 109 & 2 \\
\hline
\end{tabular}


Table 3 Summary of results with respect to health status

\begin{tabular}{|c|c|c|c|c|c|}
\hline Component & $\begin{array}{l}\text { Improvement }(+) \\
\text { No improvement }(-)\end{array}$ & $\begin{array}{l}\text { Number of } \\
\text { studies }\end{array}$ & $\begin{array}{l}\text { Range of } \\
\text { mean ages }\end{array}$ & $\begin{array}{l}\text { Sample } \\
\text { sizes }\end{array}$ & $\begin{array}{l}\text { Follow-up } \\
(\mathrm{FU})^{\mathrm{a}}\end{array}$ \\
\hline \multirow[t]{2}{*}{ Pain } & + & 3 & $57-65.5$ & 474-954 & $2-3$ \\
\hline & - & 5 & $49-77.2$ & 109-952 & $1-2$ \\
\hline \multirow[t]{2}{*}{ Disability/mobility } & + & 2 & $64-65.4$ & $416-952$ & 2 \\
\hline & - & 3 & $55-77.2$ & $109-629$ & 2 \\
\hline \multirow[t]{2}{*}{ General (self-rated) health } & + & 4 & $57-65.5$ & $474-952$ & 2 \\
\hline & - & 3 & $55-77.2$ & $109-629$ & $1-2$ \\
\hline \multirow[t]{2}{*}{ Health distress } & + & 5 & $55-65.5$ & $474-952$ & $2-3$ \\
\hline & - & 0 & & & \\
\hline \multirow[t]{2}{*}{ Fatigue/energy } & + & 4 & $55-65.5$ & $474-952$ & 2 \\
\hline & - & 2 & $49-77.2$ & $109-476$ & 2 \\
\hline \multirow[t]{2}{*}{ Social roles } & + & 3 & $55-64$ & $551-954$ & $2-3$ \\
\hline & - & 3 & $65.4-68$ & 139-952 & $1-2$ \\
\hline \multirow[t]{2}{*}{ Discomfort } & + & 0 & & & \\
\hline & - & 1 & 65.4 & 952 & 2 \\
\hline \multirow[t]{2}{*}{ Shortness of breath } & + & 1 & 64 & 954 & 2 \\
\hline & - & 3 & $49-65.5$ & $474-952$ & 2 \\
\hline \multirow[t]{2}{*}{ Anxiety } & + & 0 & & & \\
\hline & - & 2 & $49-55$ & $476-629$ & 2 \\
\hline \multirow{2}{*}{$\begin{array}{l}\text { Emotional, physical and } \\
\text { psychological well-being }\end{array}$} & + & 2 & $55-77.2$ & 109-629 & 2 \\
\hline & - & 1 & 65.4 & 952 & 2 \\
\hline \multirow[t]{2}{*}{ Quality of life } & + & 1 & 55 & 629 & 2 \\
\hline & - & 1 & 49 & 476 & 2 \\
\hline \multirow[t]{2}{*}{ Depression } & + & 1 & 64 & 954 & 2 \\
\hline & - & 3 & $49-65.5$ & $474-629$ & 2 \\
\hline
\end{tabular}

a $1=$ FU after 6 weeks;

$2=$ FU after 4-6 months;

$3=\mathrm{FU}$ after 1 year; $4=\mathrm{FU}$

after 2 years period of time. Except for the larger-scale Lorig study (1999) which reported fewer hospitalizations at the 4-month follow-up and fewer visits to a physician/AED visits at the 1-year follow-up, none of the studies found any significant changes with respect to hospitalization and physician visits.

\section{Self-efficacy}

According to Bandura (1997), who developed the selfefficacy theory, cognitive processes play an important role in the acquisition and retention of new behaviour. If people think that a certain behaviour will lead to a certain outcome, they will adopt that behaviour, but only if they consider themselves able to do so. Applied to situations of multimorbidity, belief in the ability to manage disease symptoms is expected to lead to this new behaviour.

The vast majority $(N=5)$ of all the studies that investigated self-efficacy $(N=7)$ reported an improvement (see Table 5), and the effect remained until 1 year after the end of the intervention (Lorig et al. 2003). The beneficial effect of the CDSMP on Cognitive symptom management as a way of coping with disease-related symptoms, also seems to be convincing. Four of the nine studies we reviewed 
Table 4 Summary of results with respect to health care utilization

\begin{tabular}{llllll}
\hline Component & $\begin{array}{l}\text { Improvement (+) } \\
\text { No improvement }(-)\end{array}$ & $\begin{array}{l}\text { Number } \\
\text { of studies }\end{array}$ & $\begin{array}{l}\text { Range of } \\
\text { mean ages }\end{array}$ & $\begin{array}{l}\text { Sample } \\
\text { sizes }\end{array}$ & $\begin{array}{l}\text { Follow-up } \\
(\text { FU) }\end{array}$ \\
\hline Hospitalizations & + & 1 & 65.4 & 952 & 2 \\
& - & 2 & $55-57$ & $551-629$ & 551 \\
Visits & + & 1 & 57 & $474-952$ & 2 \\
& - & 5 & $49-65.5$ & 53 \\
\hline
\end{tabular}

${ }^{\text {a }} 1=$ FU after 6 weeks; $2=$ FU after $4-6$ months; $3=$ FU after 1 year; $4=$ FU after 2 years

Table 5 Summary of results with respect to self-efficacy

\begin{tabular}{|c|c|c|c|c|c|}
\hline Component & $\begin{array}{l}\text { Improvement }(+) \\
\text { No improvement }(-)\end{array}$ & $\begin{array}{l}\text { Number } \\
\text { of studies }\end{array}$ & $\begin{array}{l}\text { Range of } \\
\text { mean ages }\end{array}$ & $\begin{array}{l}\text { Sample } \\
\text { sizes }\end{array}$ & Follow-up ${ }^{\mathrm{a}}$ \\
\hline \multirow[t]{2}{*}{ Self-efficacy } & + & 5 & $49-65.5$ & $474-954$ & $2-3$ \\
\hline & - & 2 & $68-77.2$ & $109-139$ & $1-2$ \\
\hline \multirow[t]{2}{*}{ Mental stress management } & + & 1 & 57 & 551 & 2 \\
\hline & - & 0 & & & \\
\hline \multirow[t]{2}{*}{ Cognitive symptom management } & + & 3 & $50-65.5$ & 474-952 & $1-2$ \\
\hline & - & 1 & 68 & 139 & $1-2$ \\
\hline
\end{tabular}

a $1=$ FU after 6 weeks; $2=$ FU after $4-6$ months; $3=$ FU after 1 year; $4=$ FU after 2 years

reported an improvement in Cognitive symptom management. No improvement was found only in Van Elzen's (2006) RCT of group of participants with a somewhat greater average age of 68 years. In one study, Mental stress management (as a way of coping with mental pressure from the difficulties caused by chronic diseases), according to certain cognitive self-management theories was also found to be improved by the CDSMP.

\section{Other characteristics}

We could draw no conclusions with regard to the specific influence of 'other characteristics' on the results. Diseases, translations, adaptations and attendance do not seem to lead to any systematic differences.

\section{Discussion}

The aim of our review was to evaluate the effects of the CDSMP, a program that claims to promote self-management in vulnerable older people. We identified nine studies describing eight RCTs and have presented the results in accordance with the four main domains of outcomes that are expected to improve after participation in the CDSMP: Self-efficacy, Health behaviour, Health status and Health care utilization. In order to investigate the effects of CDSMP on these four main domains, a variety of separate outcomes were studied.
Overall, the results of the studies showed that the CDSMP led to an increase in physical exercise, a decrease in health distress, an improvement in self-care and a beneficial effect on self-efficacy measures. Although there is an expected relationship between self-efficacy and wellbeing, there was no improvement in the latter after participation in the CDSMP. There was also no change in Health care utilization after participation.

There were many differences with respect to the effectivity of the program between the studies, which could neither be explained by differences in the sample sizes, the mean ages of the participants nor the follow-up period. All the studies included patients with heterogeneous chronic diseases, but the samples were rather homogeneous with regard to sex and age. Most of the participants were somewhat younger older people with an average age of 58 years, except for the study of Haas et al. (2005), which included participants with low back pain and a higher mean age. Most participants were women. The inclusion of minority or majority ethnic groups did not appear to have any clear influence on the results. Also the type of disease and other characteristics, such as translation, adaptation and attendance, showed no significant differences in effectivity of the program.

We only found eight RCTs that investigated the effectiveness of CDSMP, whereas a considerable amount of literature reporting positive results of CDSMP in studies with pre/post-test design has been published. We only included RCTs because we think that this is the only design 
suitable for testing the effects of interventions and obtaining reliable results. Well-designed RCTs can help us to understand what type of intervention promotes a specific change in behaviour, because evidence-inspired descriptions of interventions are often not specific or detailed enough to exactly replicate the study (Michie and Abraham 2004).

The effectiveness of the specific components of the CDSMP has not yet been described so far, but may be inferred from the results we reviewed. For instance, certain topics, such as exercise, which were explicitly and repeatedly addressed in the program, can be expected to have been effective. The standardized structure of formulating targets and action plans may also have influenced the outcomes. Specifically, the action plans that are formulated after each of the sessions and evaluated at the start of the next session may have led to better self-efficacy scores, because this is commonly measured with questions that focus on 'conviction in setting and realizing one's own goals'. However, whether self-efficacy beliefs really did improve is still unclear in view of the conviction that improved self-efficacy leads to greater well-being, one may indeed expect an increase in well-being with an increase in self-efficacy beliefs. However, no improvement was found in overall well-being in the reviewed studies.

As life-expectancy increases, a greater percentage of older people will have age-related diseases and may suffer from the problems that accompanies persistent health decline. Since previous research has showed that coping resources such as self-efficacy mediate the association between persistent health decline and well-being, the CDSMP could be considered a worthwhile intervention. Indeed, based on the current review the CDSMP seems a promising intervention that helps older people to face the challenge they are confronted with, to enable increase their physical activity and self-care, decrease their health distress, and to maintain self-management and thus hopefully their well-being.

Strengths of our review consist in the systematic qualitative overview we created despite the disparate presentation of the results in the various studies and the inclusion of only nine RCTs. As a shortcoming may be considered this small number of studies included. Unfortunately, we were not able to perform a meta-analyses because the outcome measures varied widely between the studies. As a consequence, it was not possible to quantify the effects of the intervention.

Thus far, no research on the effectivity of the CDSMP has focused on people of 80 years of age and above, whereas this is the group with the most chronic diseases and functional limitations that may profit the most from the intervention. Therefore, we recommend the inclusion of such a sample in a CDSMP intervention study with the aim to improve health behaviour, self-efficacy, and well-being. We then strongly recommend a high quality design as an RCT, rather than a pre-/post-test design, to provide evidence-based input for the development of feasible interventions. Also expanding outcomes with for instance, the fields of quality of life and depression (well-being), mastery and self-esteem to broaden the current narrow standard focus of the studies. Furthermore, a significant improvement is needed in the possibility to compare separate study results.

Open Access This article is distributed under the terms of the Creative Commons Attribution Noncommercial License which permits any noncommercial use, distribution, and reproduction in any medium, provided the original author(s) and source are credited.

\section{References}

\section{*Original articles included in the review}

Artistico D, Baldassarri F, Lauriola M, Laicardi C (2000) Dimensions of health-related dispositions in elderly people: relationships with health behaviour and personality traits. Eur J Pers 14:533-552

Bandura A (1977) Self-efficacy: toward a unifying theory of behavioural change. Psychol Rev 84:191-215

Bandura A (1997) Self-efficacy: the exercise of control. W.H. Freeman and Company, New York

Bisschop MI (2004a) Psychosocial resources and the consequences of specific chronic diseases in older age. The Longitudinal Aging Study Amsterdam, Chap 6. Dissertation Vrije Universiteit van Amsterdam, pp 71-88

Bisschop MI, Kriegsman DMW, Beekman ATF, Deeg DJH (2004b) Chronic diseases and depression: the modifying role of psychosocial resources. Soc Sci Med 59:721-733

Crimmins E (2004) Trends in the health of elderly. Annu Rev Public Health 25:79-98

Crimmins E, Hayward M, Saito Y (1996) Differentials in active life expectancy in the older population of the United States. J Gerontol Soc Sci 51B:S111-S120

*Elzen H, Slaets J, Snijders A, Steverink N (2006) Evaluation of the chronic disease self-management program (CDSMP) among chronically ill older persons in the Netherlands. Soc Sci Med 64:1832-1841

Folkman S, Newman S, Lamb R, Shipley M (1986) Social relationships and psychological well-being in rheumatoid arthritis. Soc Sci Med 27:399-403

Folkman S, Newman S, Lamb R, Shipley M (1988) Social relationships and psychological well-being in rheumatoid arthritis. Soc Sci Med 27:399-403

*Dongbo F, Hua F, Mc Patrick, Yi-e S, Lizhen Z, Huiqin Y, Jianguo M, Shitai Z, Yongming D, Zhihua W (2003) Implementation and quantitative evaluation of chronic disease self-management program in Shanghai, China: randomized controlled trial. Bull World Health Organ 81:174-182

*Griffiths G, Motlib J, Azad A, Ramsay J, Eldridge G, Khanam R, Munni R, Garrett M, Turner A, Barlow J (2005) Randomized controlled trial of a lay-led self-management program for Bangladeshi patients with chronic disease. $\mathrm{Br} \mathrm{J}$ Gen Pract $55: 831-837$ 
*Haas M, Groupp E, Muench J, Kraemer D, Brummel-Smith K, Sharma R, Ganger B, Attwood M, Fairweather A (2005) Chronic disease self-management program for low back pain in the elderly. J Manipulative Psychol Ther 28-24

Jang Y, Haley W, Small B, Mortimer J (2002) The role of mastery and social resources in the association between disability and depression in later life. Gerontologist 42(6):807-813

Jonker AGC, Comijs HC, Knipscheer CPM, Deeg DJH (2008) Persistent Deterioration of Functioning (PDF) and change in well-being in older persons. Ageing Clin Exp Res 20(5):461-468

Jonker A, Comijs C, Knipscheer K, Deeg D (in press) The role of coping resources on change in well-being during persistent health decline. J Aging Health

*Kennedy A, Reeves D, Bower P, Lee V, Middleton E, Richardson G, Gardner C, Gately C, Rogers A (2007) The effectiveness and cost effectiveness of a national lay-led self-care support programme for patients with long-term conditions: a pragmatic randomised controlled trail. J Epidemiol Commun Health 61:254-261

Kunzmann U, Little TD, Smith J (2000) Is age-related stability of subjective well-being a paradox? Cross-sectional and longitudinal evidence from the Berlin Aging Study. Psychol Aging 15(3):511-526

Landau R, Litwin H (2001) Subjective well-being among the old-old: the role of health, personality and social support. Int J Aging Hum Dev 52(4):265-280

Larson PC, Boyle ES, Boaz ME (1984) Relationship of self-concept to age, disability, and institutional residency. Gerontologist 24:401-407

Lorig K (1996) Chronic disease self-management: a model for tertiary prevention. Am Behav Sci 39:767-783

Lorig K, Steward A, Ritter P, Gonzales V, Laurent D, Lynch J (1996) Outcome measures for health education and other health care interventions. Sage Publications, Thousand Oaks, CA

*Lorig K, Sobel D, Stewart A, Brown B Jr, Bandura A, Ritter P, Gonzalez V, Laurent D, Holman H (1999) Evidence suggesting that a chronic disease self-management program can improve health status while reducing hospitalization: a randomized trial. Off J Med Care Sect 37(1):5-14
Lorig K, Holman H, Sobel D, Laurent D, Gonzalez V (2000) Living a healthy life with chronic conditions: self-management of heart disease, arthritis, stroke, diabetes, asthma, bronchitis, emphysema \& others. Bull Publishing Company, Palo Alto, CA

Lorig KR, Ritter P, Stewart AL, Sobel DS, Brown B-WJ, Bandura A, Gonzalez VM, Laurent DD, Holman HR (2001a) Chronic disease self-management program: 2-year health status and health care utilization outcomes. Med Care 39:1217-1223

Lorig KR, Sobel DS, Ritter PL, Laurent D, Hobbs M (2001b) Effect of a self-management program on patients with chronic disease. Eff Clin Pract 4:256-262

*Lorig K, Ritter P, Gonzalez V (2003) Hispanic chronic disease selfmanagement. A randomized community-based outcome trial. Nurs Res 52(6):361-369

Michie S, Abraham C (2004) Interventions to change health behaviours: evidence-based or evidence inspired? Psychol Health 19:29-49

*Richardson G, Kennedy A, Reeves P, Bower V, Lee E, Middleton C, Gardner C, Gately C, Rogers A (2008) Cost effectiveness of the Expert Patients Programme (EPP) for patients with chronic conditions. J Epidemiol Community Health 62:361-367

Robine JM, Mitchel JP (2004) Looking forward to a general theory on population aging. J Gerontol A 59(6):M590-M597

Schram M, Frijters D, van de Lisdonk E, Ploemacher J, de Craen A, de Waal M, van Rooij F, Heeringa J, Hofman A, Deeg D, Schellevis F (2008a) Setting and registry characteristics affect the prevalence and nature of multimorbidity in the elderly. J Clin Epidemiol 5:1104-1112

Schram MT, de Waal MWM, de Craen AJM, Deeg DJH, Schellevis FG (2008b) Multimorbidity; the new epidemie. Tijdschrift voor Gezondheidswetenschappen 86(1):23-25

Steverink N, Lindenberg S, Slaets J (2005) How to understand and improve older people's self-management of well-being. Eur J Ageing 2:235-244

*Swerissen H, Belfrage J, Weeks A, Jordan L, Walker C, Furler J, McAvoy B, Carter M, Peterson C (2006) A randomised controlled trial of a self-management program for people with a chronic illness from Vietnamese, Chinese, Italian and Greek backgrounds. Patient Educ Couns 64:360-368 